دور معلمات رياض الأطفال أثناء فترة الوجبة في إكساب الثقافة الغذائية لأطفال الروضة بعفيف، المدلكة العربية السعودية

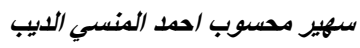

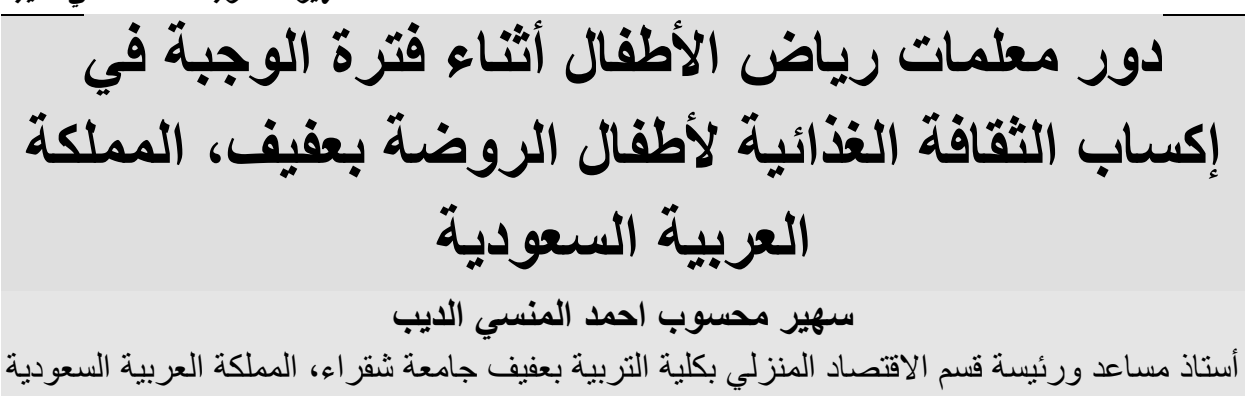

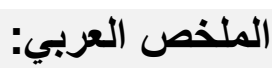

هدفت هذه الدراسة إلى تقييم دور معلمات رياض الاطفال في إكساب الثقافة الغذائية لطفل

الروضنة أثناء فترة تناول الوجبة، ولتحقيق هذا تم أولا اخذ خطاب بالموافقة على اجراء الدراسة من

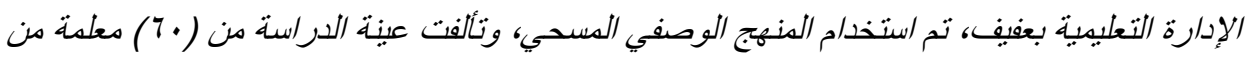
معلمات رياض الأطفال في الروضات التابعة للإدارة التعليبية بعفيف، تم اختيارهن بطريقة العينة العشوائبة، استخدام الاستبيان والمقابلة كادوات لجدع البياناتُ وباستخدام البرنامج الاحصائسي (Spss) في تحليل البيانات. أظهرت نتائج الدراسة أن الاداة قد حصلت على متوسط عام بلغ (90, r من گ)، وعلى مستوى المجالات؛ حصل محور (مفهوم الثقافة الغذائية على متوسط r, r بلبيه محور الصعوبات

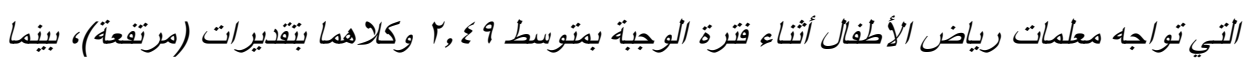
بواققن ببرجة مرتفعة جدا على مدارسات معلمات رياض الأطفال خلال فترة الوجبة بكتوسط (7 ع,"r)، كما أشارت المعلمات في المقابلات ان هنالك وعي من قبل الأسر في نوع الغذاء المقدم للأطفال وذلك من خلال الوجبات التي يحضرها الاطفال. وفي ضوء نتائج هذه الدراسة تم تقديم عدد من التوصيات و المقترحات لإنخال الثقافة الغذائية للطفل كمقررات في تأهيل وتلدريب المربيات والمعلمات.

الكلمات المفتاحية: فترة الوجبة، الثقافة الغذائية، رياض الأطفال. 
الدراسات على مواصفاتها ومكوناتها وفوائدها والنشاطات المصاحبة لها فهي

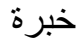

تعلمية غنية بالمواقف الاجنماعية و الحركية والقيمية والعلمية التي يكتسبها

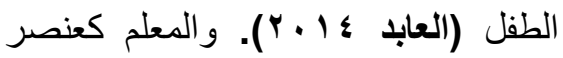

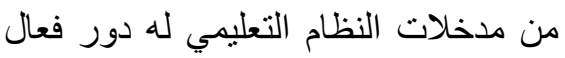

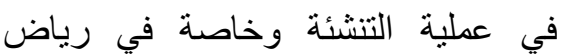
الأطفال (Trudy, \&Vicki, 2012) حيث يشكل القدوة التي تؤثر على اكتساب الأطفال للمفاهيم و العادات الغذائية

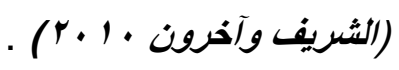

العلاقة بين خصائص معلمة الروضة واكتساب الطفل للخبرات علاقة

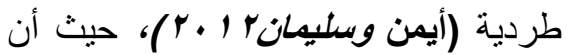
التغذية في هذه المرحلة لا تعني توفير

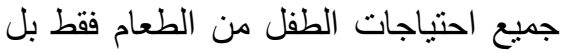

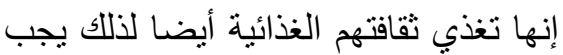
على الآباء والعاملين في رياض الأطفال الطال الطال

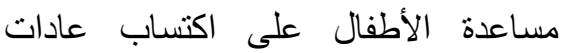

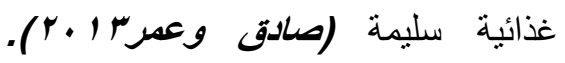
ورغم تللك الأهمية لدور المعلم كعامل مؤثر في تنشئة الطفل وخاصة في مجال اكتساب العادات الغذائية السليمة، الا فان في في الدراسات في هذا المجال وخاصة في الدئ مجال فترة الوجبة يعد محدودا. أوضحت الوت في

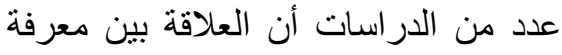

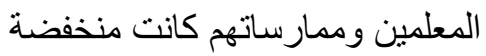

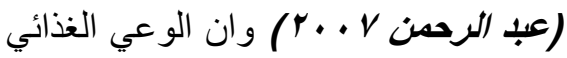
للمتخصصات في رياض الأطفال منوسط الغران

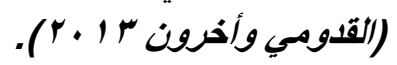

المقدمة

تُعد مرحلة رياض الأطفال من

المراحل الهامة جداً و الحاسمة في صحة لإنة الطفل المستقبلية، ذلك لأنها الفترة التي يتم

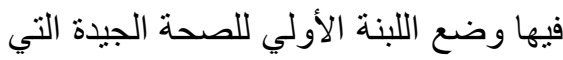
تتبلور ملامحها، وتظهر في مستقبل حياة الفرد، كما أنها تتأثر بالسلوك و والمعارف

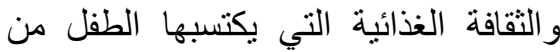

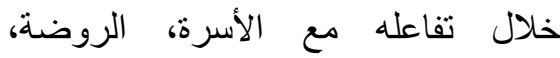

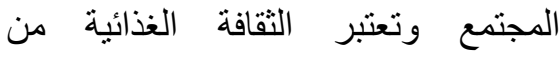
الموضوعات الهامة بالنسبة للأطفال،

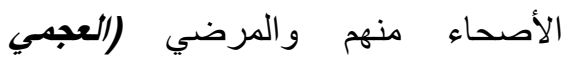

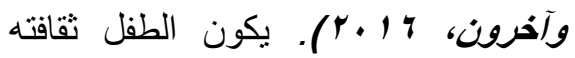
الغذائية من خلال ما يحيطه من مؤثرات وما يمارسه يوميا أو يمارس أمامه. فإذإ

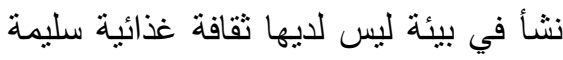
سوف تترجم إلى عادات غذائية غير سليمة مما يؤثر سلبيا على صحتها.

يعد تدريب الأطفال على العادات

الغذائية الصحيحة من أهم أدوار معلمة الإنة

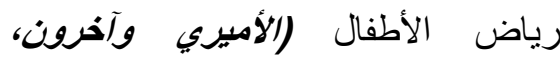

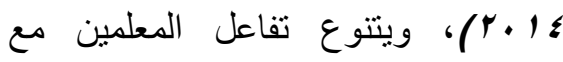

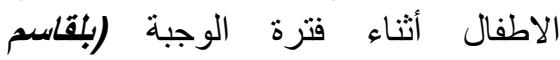

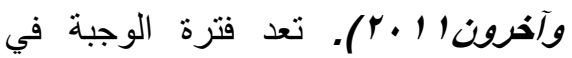
الروضة نشاط تربوي إذ يخطط لها كنشاط لفاط تعليمي يقصد فيه استفادة الأطفال الصحية و الغذائية ومتعة المشاركة الجماعية حول الإلئ

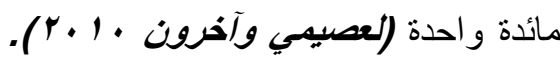
و هي من الفترات الأساسية و الثنابتة خلال فترات الجدول اليومي، وتعد فترة الوجبة التية

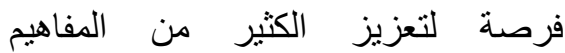
وبالدرجة الأولي التغذية السليمة، وركزت 
- ما هي الصعوبات التي تواجه معلمات رياض الأطفال في تعليم الثقافة الغذائية

$$
\text { أثناء فترة الوجبة؟ الاطن }
$$

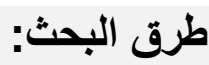

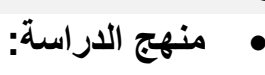

انتهجت الدراسة المنهج الورسة الوصفي

التحليلي.

\section{• مجتمع الار اسة:}

يشمل مجتمع الدراسة الأه معلمات

رياض الأطفال في مدينة عفيف بالمملكة العربية السعودية حيث تم أو لا أخذ خطاب الاطفي موافقة الإدارة التعليمية بعفيف على اجراء الهاء

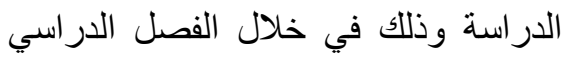

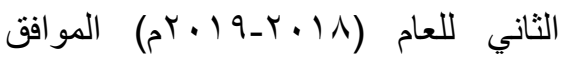

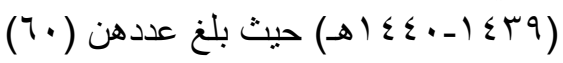
معلمة من (· (1) مدارس رياض اهـ الأطفال الحكومية و(r) مدارس رياض (ب) مداض الأطفال الأهلية.

\section{• عينة الدراسة:}

تم اختيار العينة بالطريقة

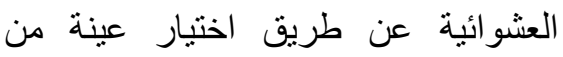

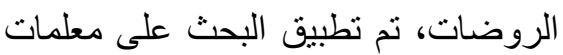

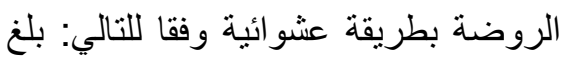

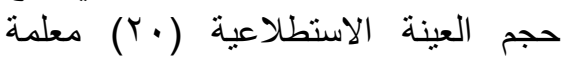
رياض أطفال من روضات حكومية و أهلية

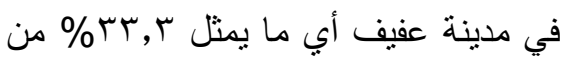
حجم مجتمع الدر اسة وهي نسبة مقبولة في الدر اسات المسحية

.(yin,2011)
كون الوجبة المدرسية فرصة للتعلم في رياض الأطفال

(Carson,20016) فقد ركزت

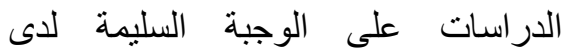
الأطفال من حيث عناصر ها أو أثر برنامج الثي الثيات غذائي محدد لفئات من ذوي الاحتياجات

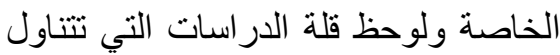
معرفة المعلمة للتغذية السليمة والثة الثقافة الغذائية، وسلوكها أثناء فترة الوجبة. بما أن عملية تطوير رياض فئل الأطفال بنبغي أن تشمل جميع مكونات

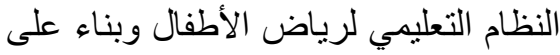
الحاجة إلى التعرف على الواقع ومشكلاتها لـانه

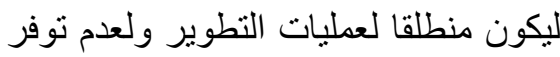
دراسات تشخص و واقع الممارسات التعليمية لمعلمات رياض الأطفال في منطقة عفيف. وبناء على ملاحظة الباحثة للأطفال في الروضة كمعلمة. و الأطفال في مي ملي المجتمع المحيط بها وما تجده من سلوكيات الأطفال نحو الغذاء، كل ذللك كان دافعا لدراسة ممارسات معلمات رياض الأطفال

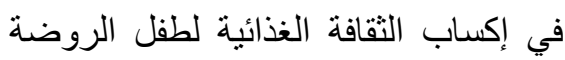
أثناء فترة الوجبة. هدف وأسئلة الدراسة: يمكن حصر مشكلة الدراسة في الأسئلة التالية - ما مفهوم الثقافة الغذائية لدى معلمات رياض الأطفال بعفيف؟ مهوم الفافه

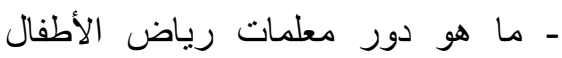
خلال فترة الوجبة مونج 


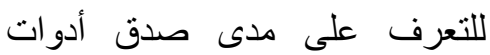

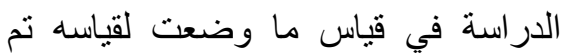

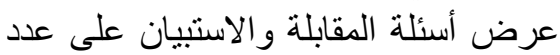

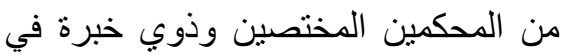
مجالات البحث العلمي وذلك للحكم على ونى صدقها، وأجرت التعديلات اللازمة في ولات التهي ضوء توصيات هيئة التحكيم، هنى أصبحت الأداة في صورتهات النهائية (الاستبيان و أسئلة المقابلة).

r- صدق الاتساق الداخلي للأداة: بعد تحقيق صدق المحكمين لأداة

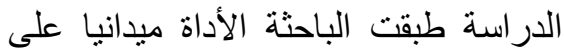

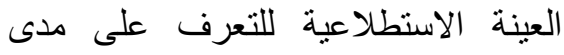
الصدق الداخلي للاسنبيان وتم الانه Pearson معل ارتباط بيرسون "Correlation" بين درجة كل عبارة من عبارات الاستبيان بالدرجة الكلية للمحور الذي تنتمي إليه، ويبين الجدول بالئل

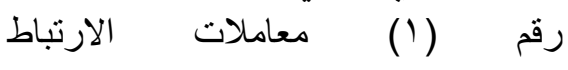

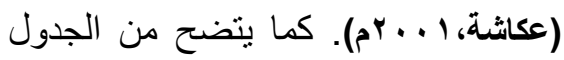

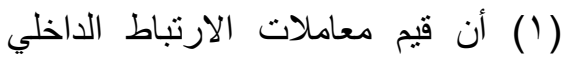

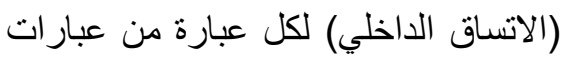

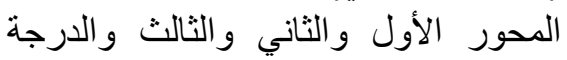

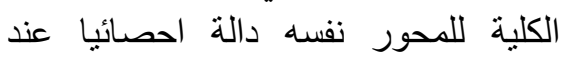
مستوى الدلالة (1 (·, •) باستثناء العبارة رقم (1') في المحور الثالث حيث مستوى (1) بلث دلالتها عند (0., ر) وهذا ما يؤكد أن

\section{عينة استطلاعية: تكونت عينة}

الدراسة الاستطلاعية من (r. (r)

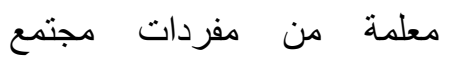
الدر اسة.

عينة أساسية: تألفت عينة البحث

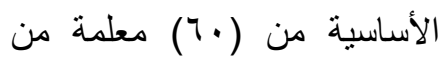

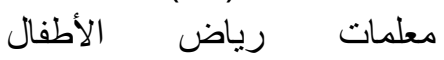
الحكومية والاهلية التابعة للإدارة

التعليمية بعفيف.

$$
\text { أدوات الدراسة: }
$$

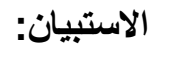

جمع البيانات من عينة المعلمات وتتضمن

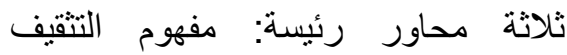
الغذائي، دور معلمات رياض رئه الأطفال،

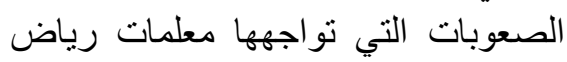
الأطفال أثناء فترة الوجبة. وتئت وتم اعداد

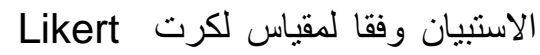

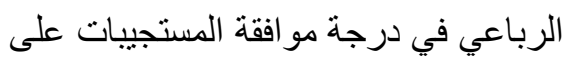

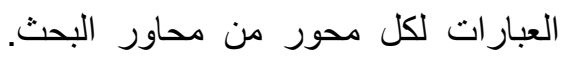

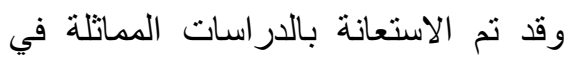
بناء الاستبانة مثل در اسة

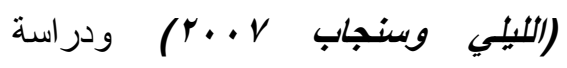
.(Barkley,2010)

\section{أولا: المقابلة الثخصية}

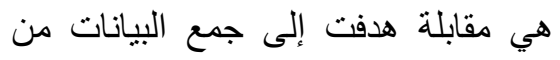
المعلمات وتفسير بعض البيانات التي تنتج عند تحليل الاستبيان. تقدير صدق الاستبانة وأسئلة المقابلة ومن الان التئن أجل التحقق من صدق أداة الدراسة 
الإجابة على هذا السؤال تم استخدام

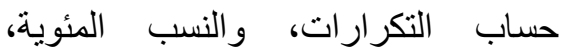

و المتوسطات الحسابية، و والانحر اف الف

المعياري و الرتب لإجابات مفردات عينة

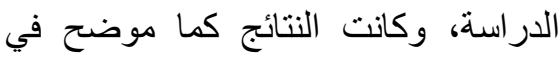

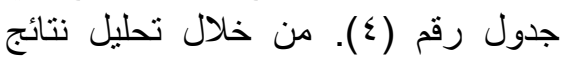
الجدول رقم (ع) (ع) تنبين أن استجابات مفردات عينة الدراسة بالنسبة العبارات المتعلقة بمفهوم الثقافة الغذائية لاى معلمات النات

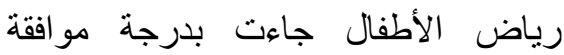

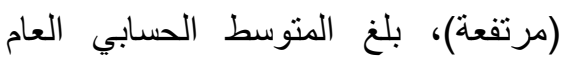
لاستجاباتهن ( المتوسط يقع في الفئة الثالثة من المقياس

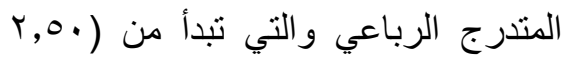

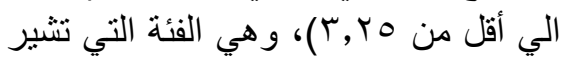
الي درجة موافقة (مرتفعة) على ألى أداة الدراسة. تراوحت المتوسطات الحسابية لعبارات محور مفهوم الثقافة الغذائية لاى لئى

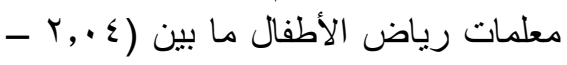

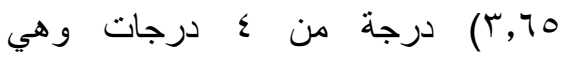
منوسطات تقع في الفئات الثانية والثالثة درهات و الرابعة من المقياس المتندرج الرباعي في لفي

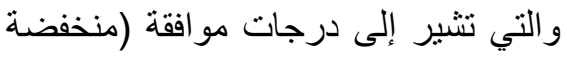
ـمرتفعة - مرتفعة جدا) بالنسبة لأداة الدراسة وهذه النتائج تتفق مع ما وجدة بـال

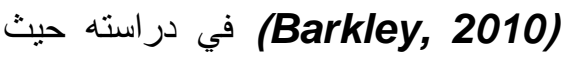
أكد على دور مربيات الروضة في بناء الثقافة الغذائية لطفل الروضة الروبة (المراسي وآخرون 1 (r)

الإجابة عن السؤال الثاني: ما ممارسات معلمات رياض الأطفال خلال

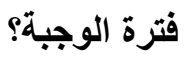

عبار ات المحاور الثناثة تتمتع بدرجة يمكن

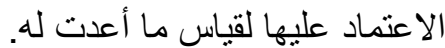

ثانيا: تقدير ثبات الاستبيان: أن تعطي أداة جمع البيانات نفس نسات

النتائج إذا أعبد استخدامها مرة أخرى تعت الحت

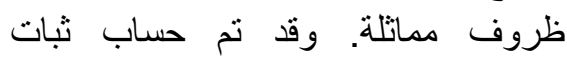
الاستيان بالتطبيق علية باستخدام معامل

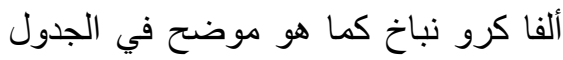

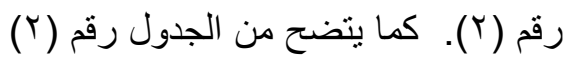

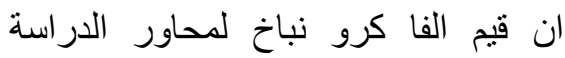

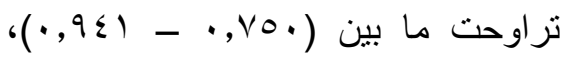

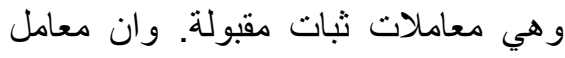

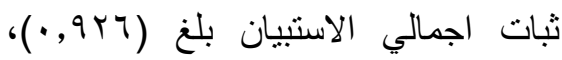

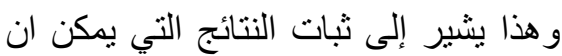

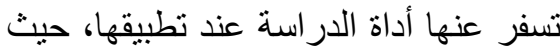
تثير الدراسات إلى أن معامل الثبات يعد الثدان

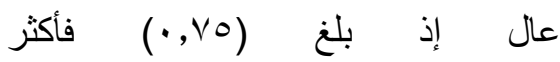

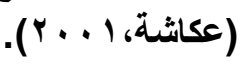

\section{ثالثا:أساليب المعالجة الإحصائية المستخدمة في الاراسة:} نم ترميز و إدخال البيانات إلى فئل

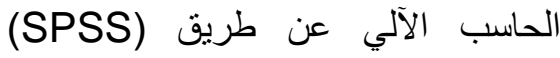

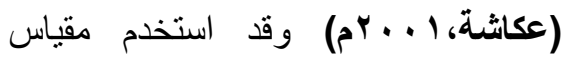

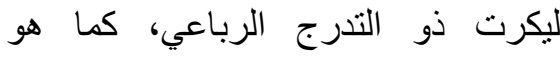

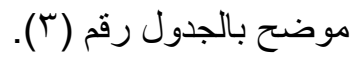

\section{عرض النتائج ومناقشتها:} ا ـ نتائج الاستبيان الجنان ومنابع

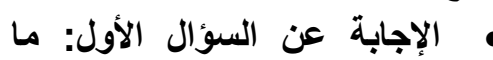
مفهوم الثقافة الغذائية لاى معلمات الأن رياض الأطفال؟ 
وجد ان مستوى (Clark, 2016). الثقافة الغذائية لدى معلمات رياض الأطفال منخفض ويحتاج الى مزيد من التدريب رياضي الاطلي و النطوير

\section{الإجابة عن السؤال الثالث ما} الصعويات التي تواجه معلمات رياض

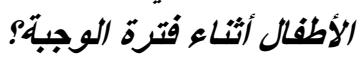
للإجابة عن هذا السؤال:

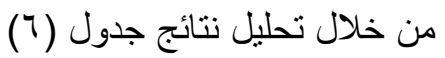
يتضح أن استجابات مفردات عينة الدراس تلاستة

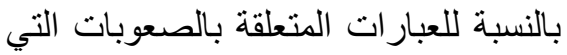
تواجه معلمات رياض الأطفال أثناء فترة

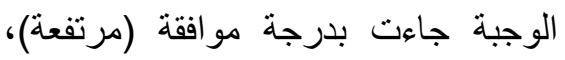

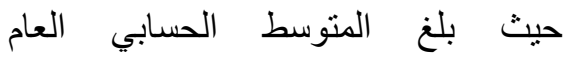

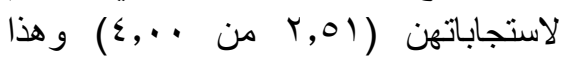
المتوسط يقع في الفئة الثالثة من المقياس

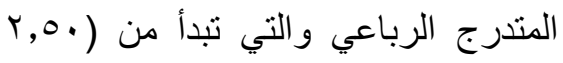

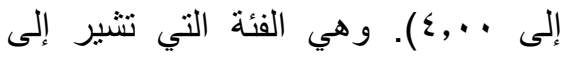

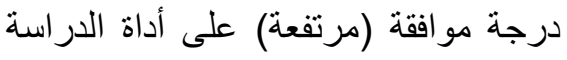

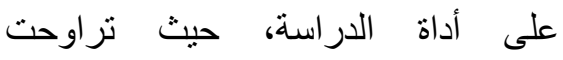

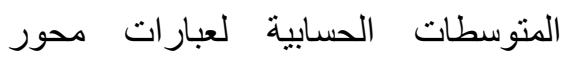

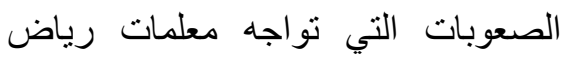

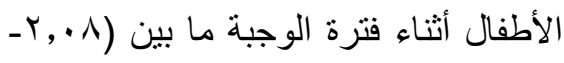

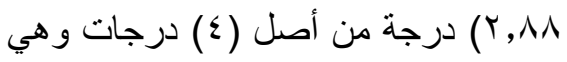
متوسطات في الفتتين الثانية و الثالثة و اللتان

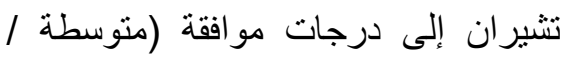
مرتفعة) على التو الي بالنسبة لأداة الدراسة

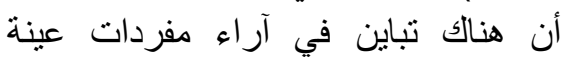

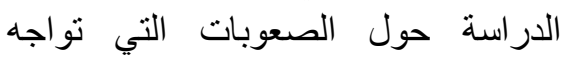
معلمات رياض الأطفال أثناء فترة الوجبة لتول

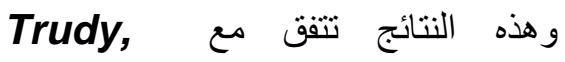
(\&Vicki, 2012) الصعوبات التي تواجه معلمات رياض
تم استخدام حساب التكرار، والنسب المئوية والمتوسطات الحسابية

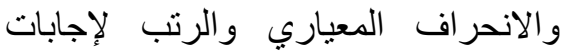
مفردات عينة الدراسة، وجاءت الناءت النتائج كما لإنات

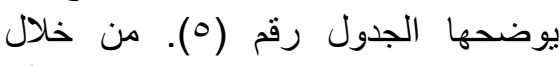
تحليل نتائج جدول رقم (0) يتضات (0) بن أن استجابات مفردات عينة الدراسة بالنسبة

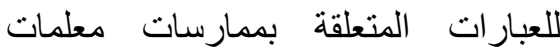
رياض الأطفال أثناء فترة الوجبة جاءت

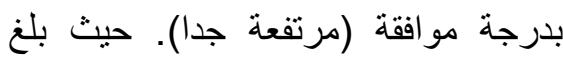

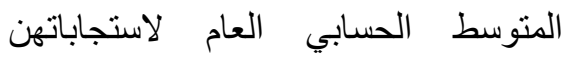

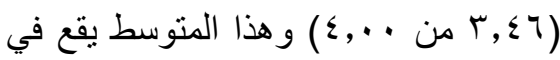

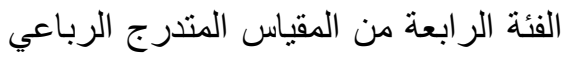

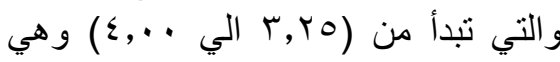

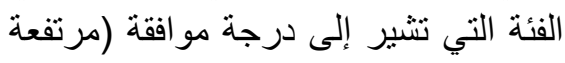
جدا) على أداة الدراسة. المتوسطات الحسابية لعبارات محور ممارسات معلمات رياض الأطفال خلال

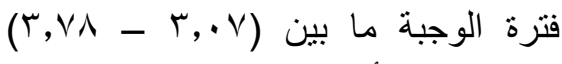

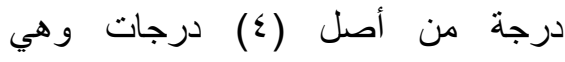

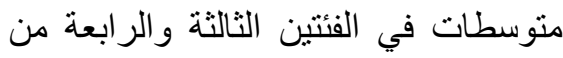
المقياس المتدرج الرباعي واللتان تشيران

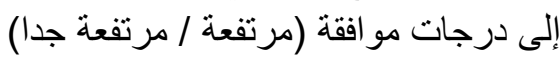

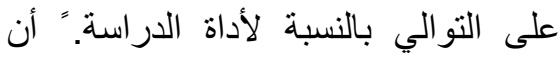
هناك شبه توافق في آراء مفردات عينة

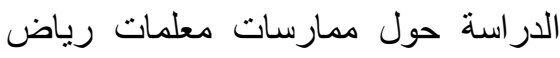

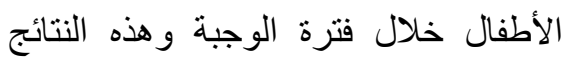

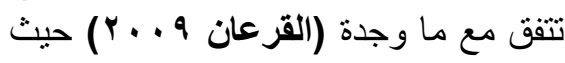

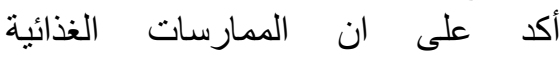
و السلوكيات التي تصدر من معلمات الإن رياض الأطفال تعتبر اللبنة الاولي في بناء

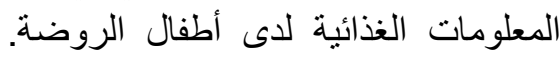

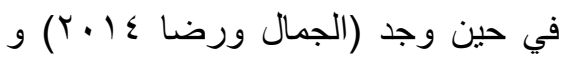


لإكساب الأطفال الثقافة الغذائية، مثل مواد حسية كإحضار طعام حقيقي

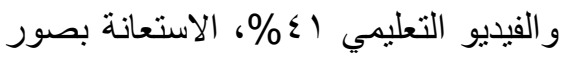

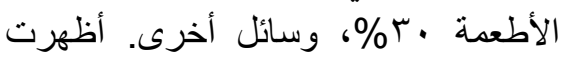

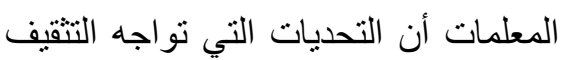
الغذائي للطفل كانت: صعوبة النقان تقبل الطفل

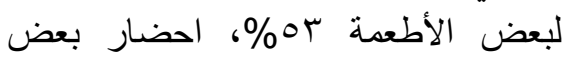

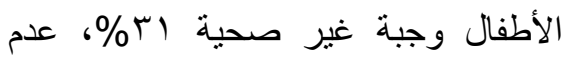

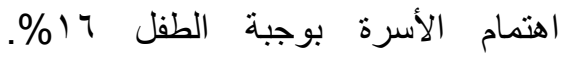

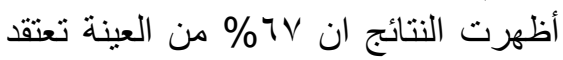

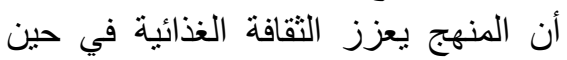

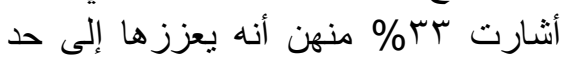
ما. أوضحت بr\% من معلمات العينة ان

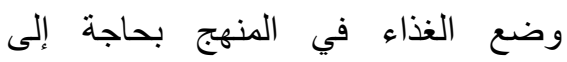
التطوير وأن تتضمن مفاهيم أكثر عن التهاء

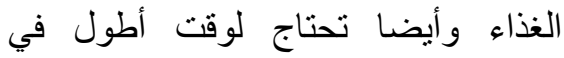

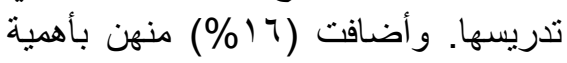

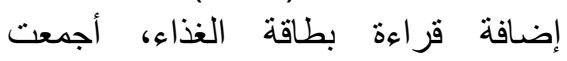

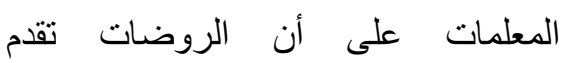
مشروعات تخص التغذية مثل يوم الغذاء

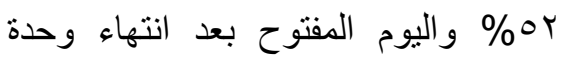

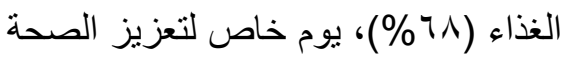

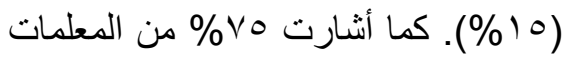
أن لدى الأطفال اتجاهات إيجابية تجاه النشاطات المتعلقة بالتغذية فهم يتسمون بالحماس وييدون سعداء ويتنافسون في بلئ احضار الطعام المفيد وملتزمين بذألكي.

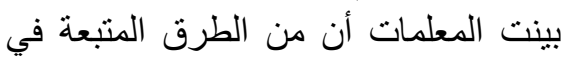
اشراك وتحسين الثقافة الغذائية للأطفال

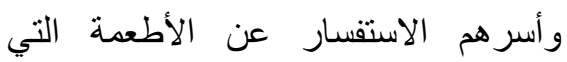
يفضلها الطفل، تتفيذ دورات تثتيفية للأهل، الألهي الالتزام بتطبيق الشروط الخاصة لإعداد وجبة غذائية متكاملة.
الأطفال في اثناء الوجبة تؤثر بدرجة كبيرة على السلوك الغذائي.

ثانيا: نتائج المقابلة الثخصية: ركزت المقابلات الثخصية على الثى

التعرف على الثقافة الغذائية وممارسات

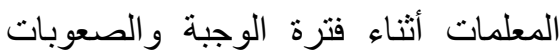
التي تواجه المعلمة، وقد دلت نتائج المقابلة المبلة الثخصية على التالي: تهتم المعلمات أثناء

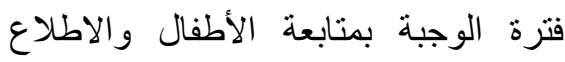

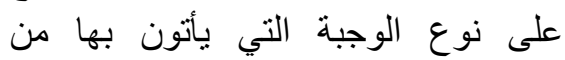

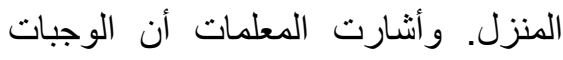

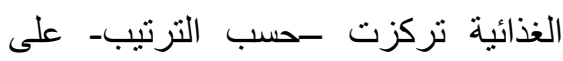

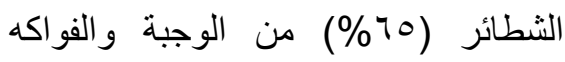

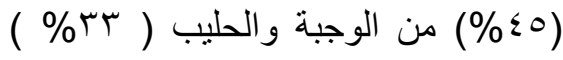

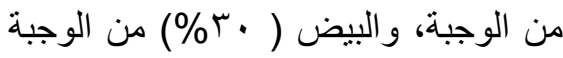

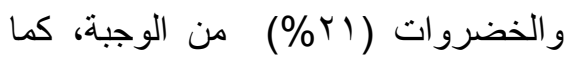

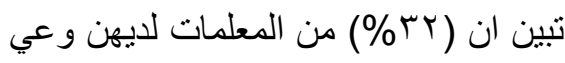
فيما يجب أن تتضمنه ونبة البطات الطفل.

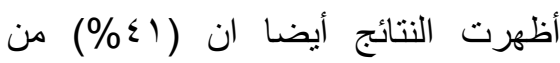
المعلمات أن مصادر الثقافة الغذائية لديهن أناء

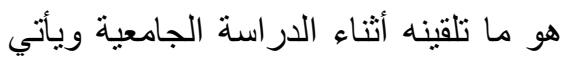
الاطلاع و القراءة في المرتبة الثانية. تقيم

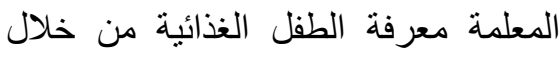

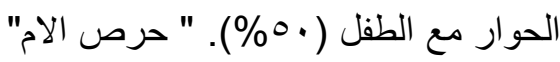

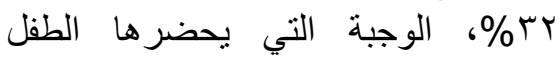

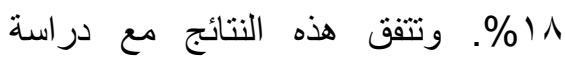

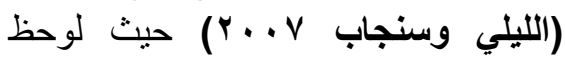
انخفاض في معدلات استهلاك الخضر

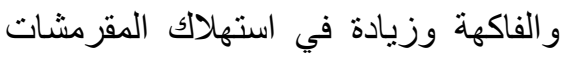
والسكريات المفرطة في وجبات الأطفال

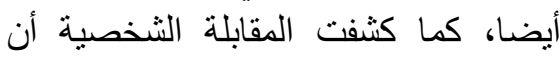
المعلمات يستخدمن مواد تعليمية متنوعة المقابة 
• أعزز سلوك الطفل الإيجابي في

التغذية.

• أنبه الأطفال إلى أهمية إتمام

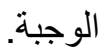

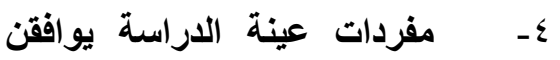

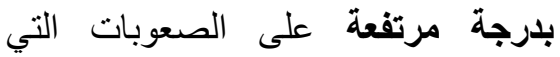
تواجه معلمات رياض الأطفال أثناء فترة

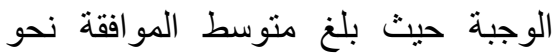

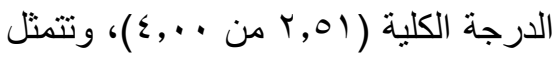

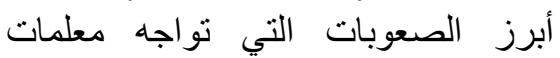
رياض الأطفال أثناء فترة الوجبة من وجهة نظر هن في الترتيب: • لا نوفر الروضة ونية وجبات صحية بديلة.

• ن نعاني من قلة البرامج التنريبية الخاصة بالثقافة الغذائية.

• تفقتر وزارة التعليم لسياسات واضحة تجاه وجبة الطفل. وقدة

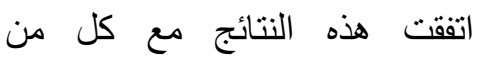
الدراسات السابقة في عدد من النقاط

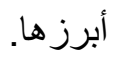

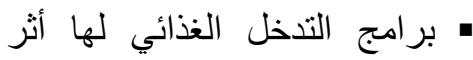
إيجابي على الأطفال (المراسي لني

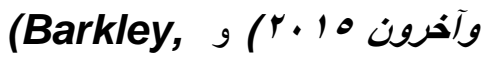
(2010) بالتغذية وممارساتهم منخفضة

(Clark, 2016).

\section{الخلاصة لنتائج الاراسة:}

أهم النتائج المتعلقة بالإجابة عن أسئلة

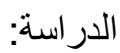

1. مفردات عينة الدراسة يوافقن بدرجة مرتفعة على مفهوم الثقافة الغذائية،

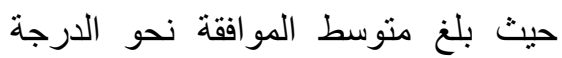

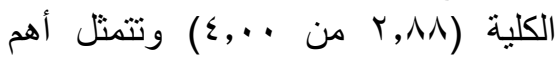
مفاهيم الثقافة الغذائية من وجهة نظر هن في الترتيب: • يمكن نعزيز الثقافة الغذائية أثناء

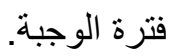

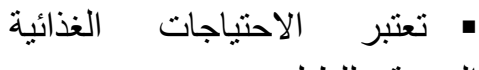
اليومية للطفل جزء من مفهوم الاحتية الثقافة الغذائية.

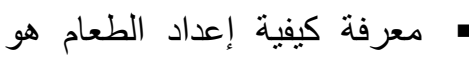
جزء من مفهوم الثقافة الغذائية.

r- مفردات عينة الاراسة يوافقن

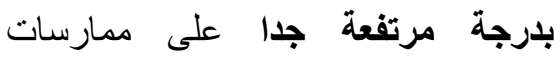
معلمات رياض الأطفال خلال فترة الوجبة

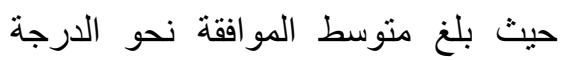

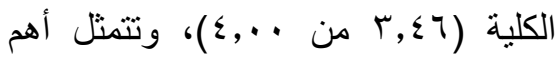
ممارسات معلمات رياض الأطفال خلال

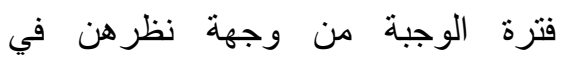
• أبادر بتطبيق قوانين الوجبة فأكون نموذجا للأطفال. 


$$
\begin{aligned}
& \text { • أن الوعي الغذائي للمتخصصات } \\
& \text { في رياض الأطفال منوسط (الجمال }
\end{aligned}
$$

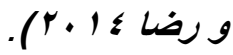

• أن الوجبة المدرسية فرصة للتعلم

Trudy, ي رياض الأطفال

(\&Vicki, 2012)

$$
\text { الغذاء اختلاف في آراء العاملين حول المركية }
$$

(Derscheid,2014)

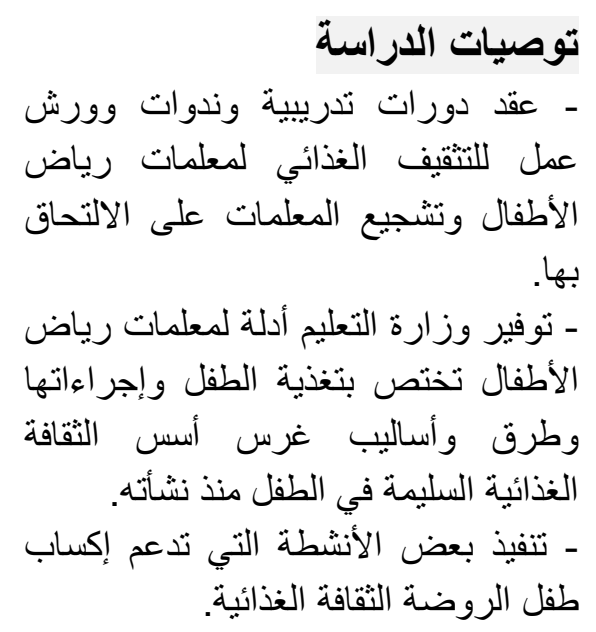
- عقد دورات تدريبية وندوات وورش

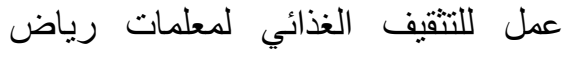

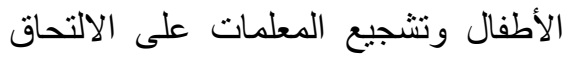
بـ

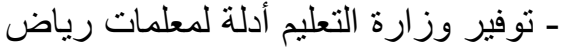
الأطفال تختص بتغذية الطفل وإجراءاتها

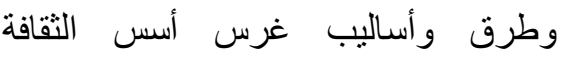
الغذائية السليمة في الطفل منذ نشأته. طفل الروضة الثقافة الغذائية. 
التثقيف الغذائي، دار الفكر للنشر

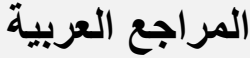

و التوزيع طا، عمان.

شادية احمد الثريف، وبيضاء محمد

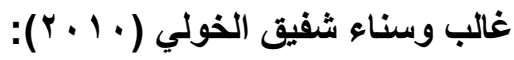

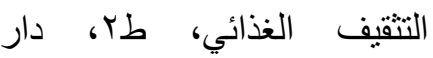

المسيرة للنشر، عمان.

أبا القسم خضر صادق، ومنى محى (بر)

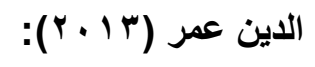

مفاهيم حديثة في تغذية الأطفال،

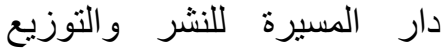

و الطباعة(ط الم ) عمان.

شريف بادي الليلي ورويدا خضر

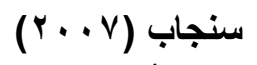

أثر الوعي والممارسات الغذائية

لعينة من معلمات رياض الأطفال

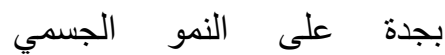

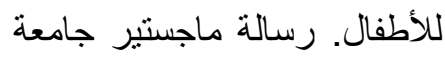

الملك عبد العزيز كلية الاقتصاد

المنزلي و التربية الفنية

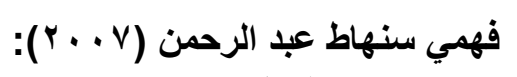

صحة الطفل وتغذينه، طع، دار لار

الفكر للنشر والتوزيع، عمان.

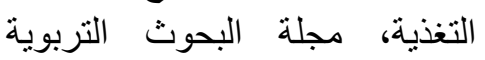

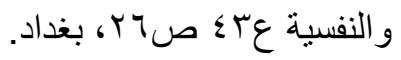

$$
\text { رضا مسعد العابد (ع 1 + r): }
$$

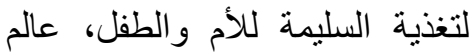

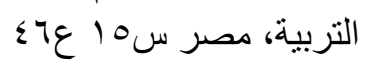

عواض سطام الجمال، رضا مسعد

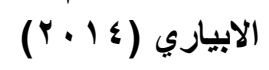

الجابرية غطاس العصيمي، ونجمة خالد

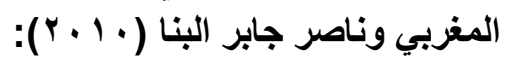

الوجبة الغذائية و وعلاقتها

بالطفل في رياض الألة الطفال

مجلة النطوير التربوي. ساضو الاطفو

علهo سلطنة عمان.

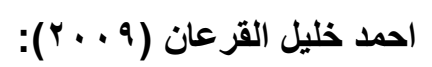

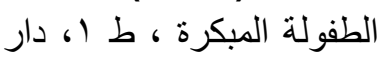

الإسر اء للنشر ، عمان

حياة عبد الواح القدومي، وعماد

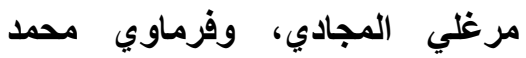
الطريس (r المبادي،

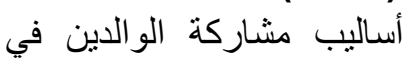

برنامج رياض الأطفال في في الوبن

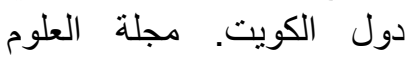

التربوية. عَr. معهد الدراسات

والبحوث التربوية.

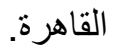

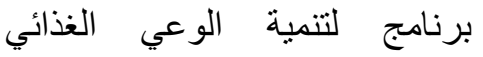
الصحي لأطفال الحضانة و علاقته

سلامة علي المراسي ، سونيا نبيل

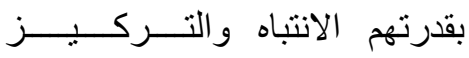

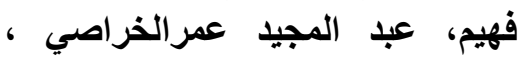

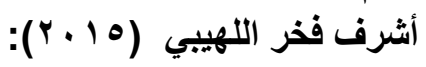


منى رزق بلقاسم ، يونس مدار رايسي،

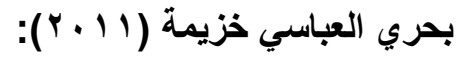

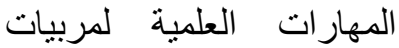

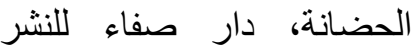

$$
\begin{aligned}
& \text { و التوزيع (ط () عمان }
\end{aligned}
$$

هبة محمد العجمي ، ضعى ضعى خليل القرعان؛ مهاي عامر العاني، الأميري

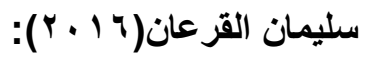

أثز التصحيح الزائد في تعديل

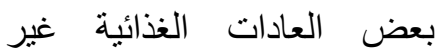

السليمة لدى الأطفال المصابين

بسوء التغذية. مجلة البحوث

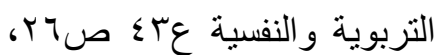

بغداد
مجلة الطفولة و التنمية عـأريا

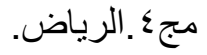

محمد نجيب أيمن، و الفراهدي عبد

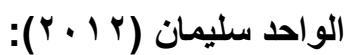

موسوعة غذاء وتنغذية الطفل.: طس، دار يافا للطباعة و النشر ـ لبنان

محمد عامر الأميري، هبة حسين

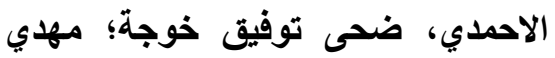

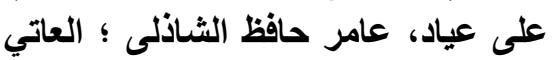

أثز التصحيح الزائد في تعديل بعض العادات الغذائية غير السليمة لاى الأطفال المصابين بسوء الغذانية العير

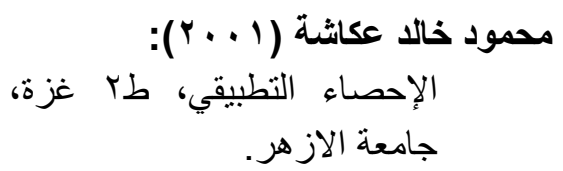


دور معلمات رياض الأطفال أثناء فترة الوجبة في إكساب الثقافة الغذائية لأطفال الروضة بعفف، المدلكة العربية السعوبية سهير محسوب /حمد المنسي الليب اليب الئي

Motherhood in a Diverse and Changing World 59 th Arlington. Georgia, $\quad 7-\quad 10$ November

Derscheid, L. E (2014):

Teachers' Self-Efficacy and Knowledge of Healthy Nutrition and Physical Activity Practices for

Preschoolers:

Instrument

Development and Validation. Journal of Research in Childhood Education 28 (2): 261276

Trudy, F., Vicki, A., (2012):

Impairments of attention following childhood Traumatic Brain Injury, child Neuropsychology, Vol. 5, No. 4, pp 213: 223,

Yin, R, K. (2011):

Applications of case study research. Sage a

(10

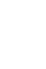

Barkley, R. (2010):

"Munch and Move: evaluation of a preschool Healthy eating and movement skill program." International Journal of Behavioral Nutrition and Physical Activity 7 (1):

80
Carson, J. (2016):
Mothers as Partners in Early Childhood Education: Comparison of an Even Start \& a Family Resource Center Program.
PH.D Brandeis University. AAT. 3342168

Clark, C, M. (2016):

Parents as Teachers. Policy Implications for Early School Intervention, Paper Presented at the Annual Conference of the MCFN Fatherhood 
دور معلمات رياض الأطفال أثناء فترة الوجبة في إكساب الثقافة الغذائية لأطفال الروضة بعفف، المدلكة العربية السعوبية

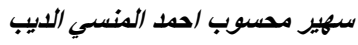

جدول (') معاملات الارتباط بين درجات كل عبارة من عبارات المحور (الاول، الثاني، الثالث) بالارجة الكلية

للمحور نفسه.

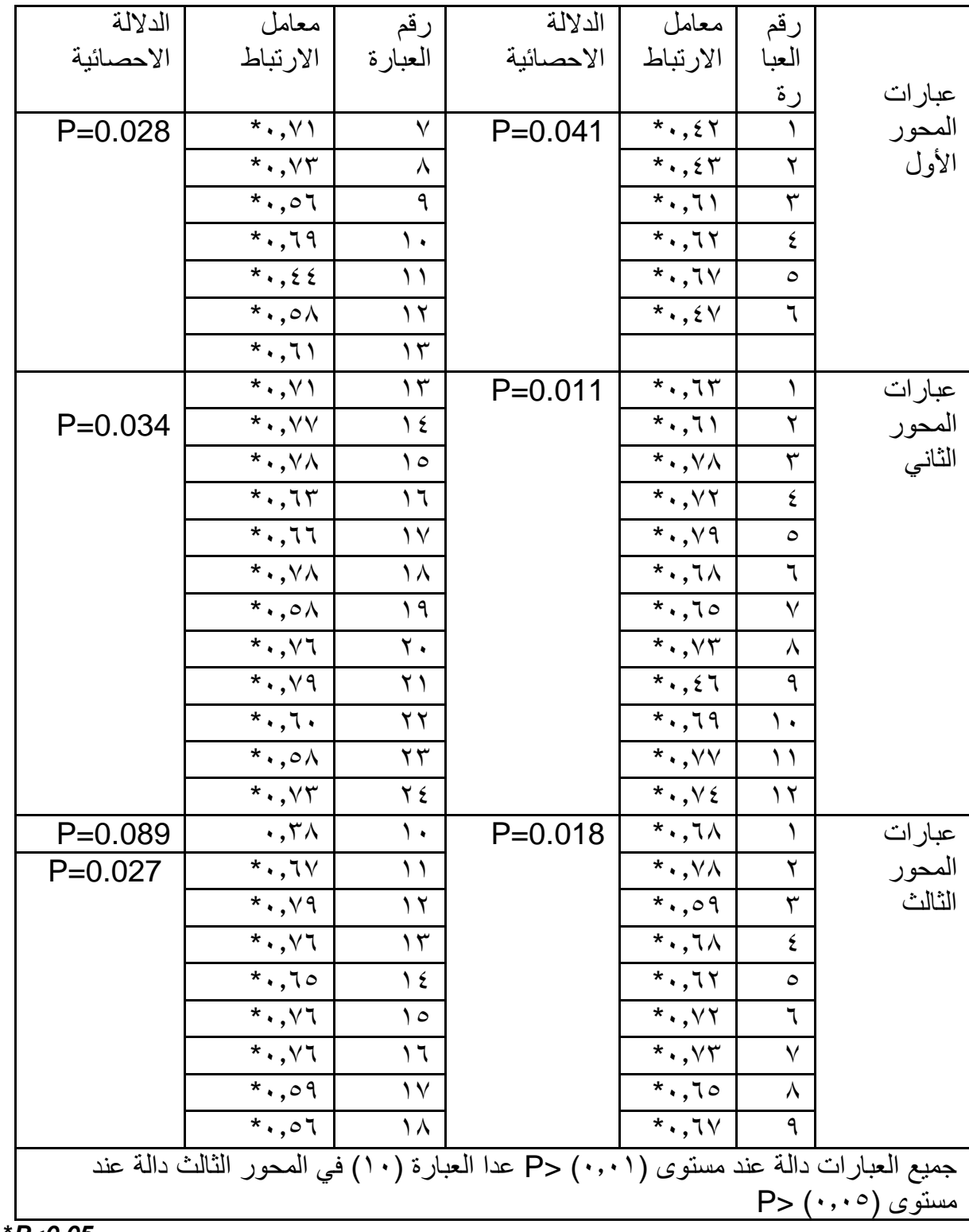

* $P<0.05$ 
جدول (ץ) يوضح قيم معامل ألفا كرونباخ لأداة الدراسة

\begin{tabular}{|c|c|c|}
\hline الفا كرونباخ & الفقرات & محاور الاستبانة \\
\hline$\cdot, \vee \vee \cdot$ & 14 & معلمات رياض الثقافة الظذائية عند \\
\hline$\cdot, 9 \leqslant 1$ & $r \varepsilon$ & ممارسات ملال فتلمات رياض \\
\hline$\cdot, q \cdot \xi$ & 11 & 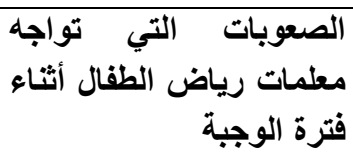 \\
\hline - 9 , & 00 & الثبات العام لأداة الدراسة \\
\hline
\end{tabular}

جدول (广ّ) يوضح طريقة تصحيح مقياس ليكرت ذو التدرج الرباعي

\begin{tabular}{|c|c|c|c|}
\hline مستوى درجة & الفئة المقابلة & الدقابلة & التّرج \\
\hline منخفضة جلا & 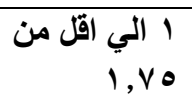 & 1 & بشدة \\
\hline منخفضة & 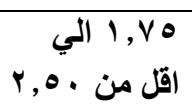 & $r$ & ارفض \\
\hline مرتفعة & اقل من ه ه, الى, & $r$ & أوافق \\
\hline مرتفعةٌ جذا & 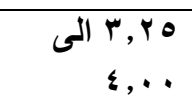 & $\varepsilon$ & بثدة \\
\hline
\end{tabular}


جدول (؛ ) التكرارات والنسب المئوية والمتوسطات الحسابية والانحرافات المعيارية والرتب لإجابات مفردات عينة الدراسة بالنسبة للعبارات المتعلقة بمفهوم

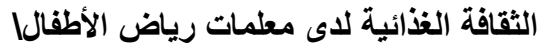

\begin{tabular}{|c|c|c|c|c|c|c|c|c|c|c|}
\hline المو افقة & ترنيب & الانحر افياري & الحسابي & بثدة & ارفض & او افق & بثندة & النسبة & العبار ات & العبارة \\
\hline \multirow{2}{*}{ بثندة } & \multirow[t]{2}{*}{1} & \multirow[t]{2}{*}{$\cdot$, Or } & \multirow[t]{2}{*}{ r,т० } & - & $r$ & IV & \&1 & ك5 & \multirow{2}{*}{ يمكن تعزيز الثقافة الغذائية } & \multirow[t]{2}{*}{$r$} \\
\hline & & & & - & $r, \mu$ & $r \wedge, r$ & $T \Lambda, r$ & $\%$ & & \\
\hline \multirow{2}{*}{ بشدة } & \multirow[t]{2}{*}{$r$} & \multirow{2}{*}{, Or } & \multirow[t]{2}{*}{$r, \Sigma \wedge$} & - & 1 & rq & $r$. & ك & \multirow{2}{*}{ تعتبر الاحتياجات الغذائية } & \multirow[t]{2}{*}{7} \\
\hline & & & & - & $1, V$ & $\varepsilon \wedge, \Gamma$ & 0. & $\%$ & & \\
\hline \multirow{2}{*}{ بشدة أو افق } & \multirow[t]{2}{*}{$r$} & \multirow[t]{2}{*}{, ro } & \multirow[t]{2}{*}{ r, ro } & - & r & ro & Tr & ك & \multirow{2}{*}{ هور جز الغذائية كيفية اعداد الطعام } & \multirow[t]{2}{*}{ V } \\
\hline & & & & - & $\Gamma, \Gamma$ & $\Delta \wedge, \Gamma$ & $r \wedge, r$ & $\%$ & & \\
\hline \multirow{2}{*}{ بشدة أو افق } & \multirow[t]{2}{*}{$\varepsilon$} & \multirow[t]{2}{*}{., 09} & \multirow[t]{2}{*}{ r, ro } & 1 & $r$ & Tr & To & 5 & \multirow{2}{*}{ الغذائبر التعامل مع النفائيات من الثقافة } & \multirow[t]{2}{*}{$\Lambda$} \\
\hline & & & & & $r, r$ & Or,T & $\varepsilon 1, V$ & $\%$ & & \\
\hline \multirow{2}{*}{ بشدة } & \multirow[t]{2}{*}{0} & \multirow[t]{2}{*}{., 01} & \multirow[t]{2}{*}{$r, r r$} & - & $T$ & $\mu_{\Lambda}$ & YI & 5 & \multirow{2}{*}{ 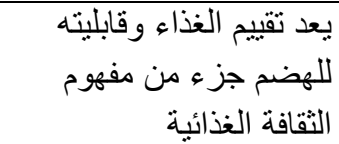 } & \multirow[t]{2}{*}{0} \\
\hline & & & & - & $1, V$ & Tr, & ro & $\%$ & & \\
\hline \multirow[t]{2}{*}{ أو افق } & \multirow[t]{2}{*}{7} & \multirow[t]{2}{*}{$\cdot, \vee \wedge$} & \multirow[t]{2}{*}{$r, \cdot r$} & $\varepsilon$ & 7 & $\Gamma \xi$ & 17 & ك5 & \multirow{2}{*}{ طرثمل مفهوم الثقافة الغذائية } & \multirow[t]{2}{*}{$\varepsilon$} \\
\hline & & & & 7,7 & 1. & $07, V$ & $r \uparrow, V$ & $\%$ & & \\
\hline
\end{tabular}




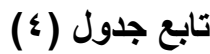

\begin{tabular}{|c|c|c|c|c|c|c|c|c|c|c|}
\hline المو افقة & ترتيب & الانحر اف المعياري & الحستوسط & بشدة & ارفض ارض & 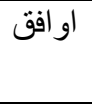 & بثندة & 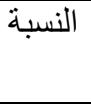 & العبار ات & العبارة \\
\hline \multirow[t]{2}{*}{ أو افق } & \multirow[t]{2}{*}{ V } & \multirow[t]{2}{*}{$\cdot, 9$} & \multirow[t]{2}{*}{ T,TT } & 9 & ir & $r$. & 9 & 5 & \multirow{2}{*}{ ما يمكن بالثقافة الغذائية كل } & \multirow[t]{2}{*}{1} \\
\hline & & & & 10 & $r \cdot$ & 0. & 10 & $\%$ & & \\
\hline \multirow[t]{2}{*}{ أرفض } & \multirow[t]{2}{*}{$\wedge$} & \multirow[t]{2}{*}{$\cdot, \vee \vee q$} & \multirow[t]{2}{*}{$Y, \Sigma \Lambda$} & $r$ & rT & 11 & V & ك & \multirow{2}{*}{ ذكر فو ائد الطعام الثقافة الغذائية على } & \multirow[t]{2}{*}{$r$} \\
\hline & & & & 0 & Or, r & $r$. & $11, \mathrm{~V}$ & $\%$ & & \\
\hline \multirow[t]{2}{*}{ أرفض } & \multirow[t]{2}{*}{9} & \multirow[t]{2}{*}{$\cdot, \wedge 9$} & \multirow[t]{2}{*}{ t, ro } & $\varepsilon$ & rq & IT & $\wedge$ & ك & \multirow{2}{*}{ 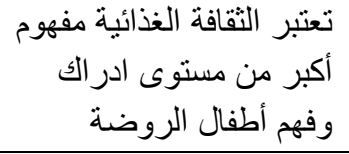 } & \multirow[t]{2}{*}{9} \\
\hline & & & & $7, V$ & 7. & $r$. & $1 T, r$ & $\%$ & & \\
\hline \multirow[t]{2}{*}{ أرفض } & \multirow[t]{2}{*}{$1 \cdot$} & \multirow[t]{2}{*}{$\cdot, V Y$} & \multirow[t]{2}{*}{ r,l. } & 1. & rq & $\wedge$ & $r$ & ك5 & \multirow{2}{*}{ صحية الأغذية غير المألوفة غير } & \multirow[t]{2}{*}{1 . } \\
\hline & & & & $17, \mathrm{~V}$ & 70 & IT, & 0 & $\%$ & & \\
\hline \multirow[t]{2}{*}{ أرفض } & \multirow[t]{2}{*}{11} & \multirow[t]{2}{*}{$\cdot, \vee_{0}$} & \multirow[t]{2}{*}{$r, \cdot \varepsilon$} & 14 & ro & 9 & $r$ & ك5 & \multirow{2}{*}{ يعتبر طعم الغذاء أهم من } & \multirow[t]{2}{*}{11} \\
\hline & & & & YI,V & $0 \wedge, \Gamma$ & 10 & 0 & $\%$ & & \\
\hline \multirow[t]{2}{*}{ 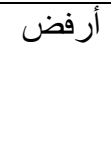 } & \multirow[t]{2}{*}{ ir } & \multirow[t]{2}{*}{$\cdot, v \varepsilon$} & \multirow[t]{2}{*}{ T, } & - & - & 14 & $\varepsilon V$ & 5 & \multirow{2}{*}{ فقصد بالثقافة الغذائية } & \multirow[t]{2}{*}{$1 T$} \\
\hline & & & & - & - & YI, & $\vee \wedge, r$ & $\%$ & & \\
\hline 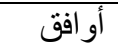 & $1 T$ & $\cdot, V Y$ & $r, Y$. & - & - & iv & $\varepsilon r$ & 5] & الثقافة الغذائية ضرورية & ir \\
\hline & & & & - & - & r^,r & 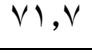 & $\%$ & لصحة الطفل & \\
\hline & & & & & ري سז, & 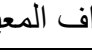 & 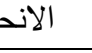 & & لمتوسط الحسابي العام Y,^^ & \\
\hline
\end{tabular}


جدول (ه) : التكرارات والنسب المئوية والمتوسطات الحسابية والاتحرافات المعيارية والرتب لإجابات مفردات عينة الدراسة بالنسبة للعبارات المتعلقة بممارسات معلمات رياض الأطفال خلال فترة الوجبة.

\begin{tabular}{|c|c|c|c|c|c|c|c|c|c|c|}
\hline المو اققة & ترنيب & الانحر افياري & الحسابي & بشدة ارفض & ارفض & او افق & بشدة أو افق & النسبة & العبار ات & ل \\
\hline \multirow{2}{*}{ أو افق بشدة } & \multirow[t]{2}{*}{1} & \multirow{2}{*}{$\cdot, \varepsilon \Gamma$} & \multirow{2}{*}{$r, \vee \wedge$} & - & - & 14 & $\varepsilon V$ & ك & \multirow{2}{*}{ فأكون نموذجاد للأطفال الوبيق انين } & \multirow[t]{2}{*}{1} \\
\hline & & & & & - & YI,V & $\vee \wedge, r$ & $\%$ & & \\
\hline \multirow[t]{2}{*}{ أو افق بشدة } & \multirow[t]{2}{*}{$r$} & \multirow[t]{2}{*}{$\cdot, \leqslant \wedge$} & \multirow[t]{2}{*}{$r, v \cdot$} & - & - & IV & $\varepsilon r$ & 5 & \multirow{2}{*}{ في أعزز سلوك الطفل الإيجابي } & \multirow[t]{2}{*}{10} \\
\hline & & & & - & - & 7,9 & $\varepsilon r, 0$ & $\%$ & & \\
\hline \multirow[t]{2}{*}{ أو افق بشدة } & \multirow[t]{2}{*}{$r$} & \multirow[t]{2}{*}{$\cdot, \leqslant 7$} & \multirow[t]{2}{*}{$r, v i$} & 1 & - & IV & $\varepsilon r$ & 5 & \multirow{2}{*}{ أنبه الأطفال الى أهمية إتمام } & \multirow[t]{2}{*}{7} \\
\hline & & & & $1, \mathrm{~V}$ & - & YA,r & $V \cdot$ & $\%$ & & \\
\hline \multirow[t]{2}{*}{ أو افق بشدة } & \multirow[t]{2}{*}{$\varepsilon$} & \multirow[t]{2}{*}{$\cdot, \leqslant 9$} & \multirow[t]{2}{*}{ r,TV } & - & 1 & 11 & $\xi$ & 5 & \multirow{2}{*}{ 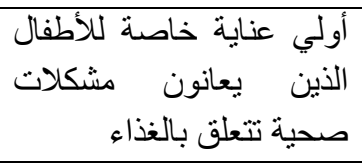 } & \multirow[t]{2}{*}{ 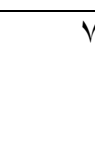 } \\
\hline & & & & - & IT & $r \cdot$ & 71 & $\%$ & & \\
\hline \multicolumn{11}{|c|}{ الانحر اف المعياري = Y Yr, } \\
\hline
\end{tabular}




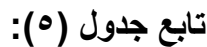

\begin{tabular}{|c|c|c|c|c|c|c|c|c|c|c|}
\hline 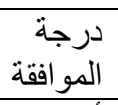 & 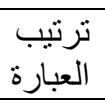 & المعياري - الانحر اف & الحسابي & بثدة - ارفض & 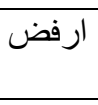 & 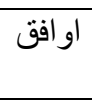 & بشدة أو افق & 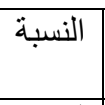 & 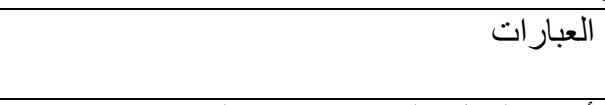 & 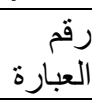 \\
\hline \multirow{2}{*}{ بشدة أوق } & \multirow[t]{2}{*}{0} & \multirow[t]{2}{*}{$\cdot, 01$} & \multirow[t]{2}{*}{$r, 7 r$} & 1 & - & Y) & ru & 5 & \multirow{2}{*}{ أشجع الطفل على تقييم وجبته الغذائية } & \multirow[t]{2}{*}{17} \\
\hline & & & & $1, V$ & - & ro & $\pi, r$ & $\%$ & & \\
\hline \multirow{2}{*}{ 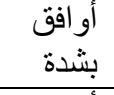 } & \multirow[t]{2}{*}{7} & \multirow[t]{2}{*}{$\cdot, \Sigma \vee$} & \multirow[t]{2}{*}{ r,70 } & - & - & YY & ro & 5 & \multirow{2}{*}{ (أوضح للأطفال كيفية التعامل مع النفايات الغذائية } & \multirow[t]{2}{*}{0} \\
\hline & & & & - & - & $r 4, \mathrm{~V}$ & $7 r, r$ & $\%$ & & \\
\hline 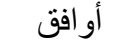 & \multirow[t]{2}{*}{ V } & \multirow[t]{2}{*}{$\cdot, \leqslant 9$} & \multirow[t]{2}{*}{ r, } & - & - & rT & $r v$ & ك & \multirow{2}{*}{ تقنتيم الطعام ، ألتنظيف، مهام تتظيمية لفترة الوجبة (الترتيب ، } & \multirow[t]{2}{*}{11} \\
\hline 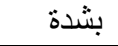 & & & & - & - & $r \wedge, r$ & $7, \mathrm{~V}$ & $\%$ & & \\
\hline 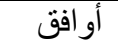 & \multirow[t]{2}{*}{$\wedge$} & \multirow{2}{*}{$\cdot, 07$} & \multirow[t]{2}{*}{ r,Tr } & 1 & - & Yr & re & ك & \multirow[t]{2}{*}{ أشرح للأطفال مفهوم ومكونات الغذاء الصحي } & \multirow[t]{2}{*}{ r } \\
\hline 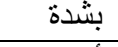 & & & & $1, \mathrm{~V}$ & - & $\mathrm{r}, \mathrm{V}$ & 71,7 & $\%$ & & \\
\hline أو افق & \multirow[t]{2}{*}{9} & \multirow[t]{2}{*}{$\cdot, 09$} & \multirow[t]{2}{*}{$r, 09$} & - & $r$ & YY & $r 4$ & ك & \multirow{2}{*}{ أستبعد الأطعمة غير الصحية من وجبة الطفل } & \multirow[t]{2}{*}{19} \\
\hline بشدة & & & & - & $r, r$ & r., V & 7. & $\%$ & & \\
\hline أو افق & \multirow[t]{2}{*}{$1 \cdot$} & \multirow[t]{2}{*}{$\cdot$, OT } & \multirow[t]{2}{*}{$r, 0 \Lambda$} & - & 1 & YT & س & ك & \multirow{2}{*}{ أشرك الأهل في تعزيز الثقافة الغذائية للطفل. } & \multirow[t]{2}{*}{ Y) } \\
\hline بشدة & & & & - & $1, \mathrm{~V}$ & $\varepsilon \Gamma, \Gamma$ & 00 & $\%$ & & \\
\hline أوافق & \multirow[t]{2}{*}{11} & $\cdot, 0 Y$ & $r, 0 \leqslant$ & $r$ & - & rV & $r$. & 5 & أتفقد و أقيم وجبة الأطفال & IT \\
\hline بشدة & & & & 0 & - & $\leqslant 0$ & 0. & $\%$ & التي يحضرونها في المنزل & \\
\hline 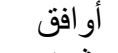 & Ir & $\cdot, 00$ & $r, 0 r$ & - & 1 & rV & rt & 5 & أرشد ذوي الطفل إلى مواصفات الوجبة الصحية & $1 \varepsilon$ \\
\hline 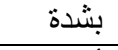 & & & & - & $1, \mathrm{~V}$ & $\leqslant 0$ & Or, r & $\%$ & للطفل واحتياجاته & \\
\hline 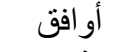 & 14 & $\cdot, 0 \leqslant$ & r,OT & r & - & rA & $r \cdot$ & 5 & أشرح للأطفال كيف يتعاملون مع أقرانهم الذين & $\wedge$ \\
\hline 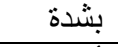 & & & & $r, r$ & - & $\varepsilon\rceil, \vee$ & 0. & $\%$ & لايهم مشكلات تتعلق بالغذاء & \\
\hline 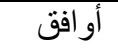 & $1 \varepsilon$ & $\cdot, 01$ & $\Gamma, \varepsilon 0$ & - & r & $r \Lambda$ & rq & ك & أوفر وجبة بديلة للأطفال الذين لم يحضروا & $r \cdot$ \\
\hline 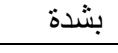 & & & & - & $\circ$ & $\Sigma 7, \vee$ & $\varepsilon \wedge, \Gamma$ & $\%$ & وجبتهم أو الذين تحتاج أسرهم إلى دعم مادي. & \\
\hline
\end{tabular}




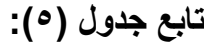

\begin{tabular}{|c|c|c|c|c|c|c|c|c|c|c|}
\hline الموجة - مرافة & 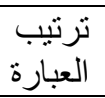 & المعياري - الانحر اف & الحستيط & بشدة ارفض & ارفض & او افق & 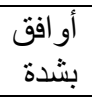 & النسبة & العبار ات & 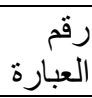 \\
\hline \multirow{2}{*}{ بش أو افق } & \multirow[t]{2}{*}{10} & \multirow{2}{*}{$\cdot, 09$} & \multirow[t]{2}{*}{$r, \Sigma T$} & - & $\varepsilon$ & $r A$ & $r A$ & 5 & \multirow{2}{*}{ 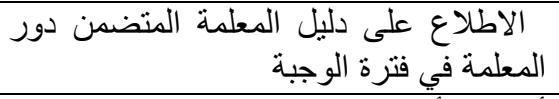 } & \multirow[t]{2}{*}{$r Y$} \\
\hline & & & & - & $7, V$ & $\sum \neg, V$ & $\sum 7,7$ & $\%$ & & \\
\hline \multirow{2}{*}{ أو افقدة } & \multirow[t]{2}{*}{17} & \multirow{2}{*}{$\cdot, 07$} & \multirow[t]{2}{*}{$r, \varepsilon \varepsilon$} & 1 & 1 & 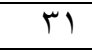 & $r V$ & ك & \multirow{2}{*}{ أشر ح للاطفال المشكلات الغذائية } & \multirow[t]{2}{*}{$\varepsilon$} \\
\hline & & & & $1, V$ & $1, V$ & 01,7 & $\leqslant 0$ & $\%$ & & \\
\hline \multirow{2}{*}{ بشدة أو افق } & \multirow[t]{2}{*}{ IV } & \multirow[t]{2}{*}{$\cdot, 0 \leqslant$} & \multirow[t]{2}{*}{$r, \varepsilon r$} & 1 & 1 & $r$ & ro & ك & \multirow{2}{*}{ 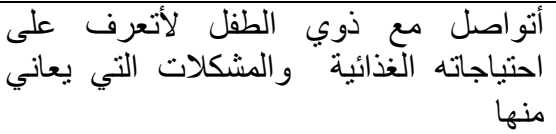 } & \multirow[t]{2}{*}{11} \\
\hline & & & & $1, V$ & $1, V$ & 00 & $\varepsilon 1, V$ & $\%$ & & \\
\hline \multirow{2}{*}{ 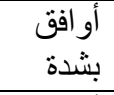 } & \multirow[t]{2}{*}{11} & \multirow[t]{2}{*}{$\cdot, 0 \mathrm{~V}$} & \multirow[t]{2}{*}{$r, \mu \nu$} & - & $\varepsilon$ & r & $r$ & 5 & \multirow[t]{2}{*}{ أبلغ الإدارة عن المشكلات الغذائية للطفل } & \multirow[t]{2}{*}{ IV } \\
\hline & & & & - & $7, V$ & 00 & $\Gamma \wedge, r$ & $\%$ & & \\
\hline \multirow{2}{*}{ 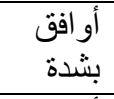 } & \multirow[t]{2}{*}{19} & \multirow[t]{2}{*}{ שT, • } & \multirow[t]{2}{*}{$r, Y q$} & 0 & $r$ & 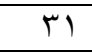 & $r 1$ & ك & \multirow{2}{*}{ خاصِية سلوك بذلك الأطفال أثناء الوجبة وفقا لمعايير } & \multirow[t]{2}{*}{1.} \\
\hline & & & & $\Lambda, \Gamma$ & 0 & $01, V$ & ro & $\%$ & & \\
\hline \multirow[t]{2}{*}{ أو افق } & \multirow[t]{2}{*}{$r}$. & \multirow[t]{2}{*}{$\cdot, 7 \varepsilon$} & $r, Y \leq$ & $V$ & 7 & Tr & 10 & ك & أعد خطة علاجية للطفل لتعزيز ثقافته & 14 \\
\hline & & & & $11, \mathrm{~V}$ & 1. & $19, Y$ & 9 & $\%$ & الغذائية & \\
\hline أو افق & Y) & $\cdot,(1)$ & $r, Y \mu$ & 7 & $\varepsilon$ & $r \cdot$ & $r \cdot$ & ك & أتنتاول وجبتي دائما مع الأطفال & r \\
\hline & & & & $1 \cdot$ & $7, V$ & 0. & $\begin{array}{ll}\mu, r \\
\mu\end{array}$ & $\%$ & & \\
\hline 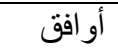 & KY & $\cdot, \vee \vee$ & $r, .9$ & 0 & 11 & rq & 10 & S & أدون أسماء الأطفال الذين لم يتتاولون & $r \varepsilon$ \\
\hline & & & & $\Lambda, \Sigma$ & $1 \wedge, r$ & $\varepsilon \wedge, \Gamma$ & 9 & $\%$ & و جبتهم & \\
\hline 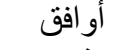 & זr & $\cdot$ & $r, \cdot V$ & - & 1 & $\wedge$ & 01 & ك & احفز الطفل على تناول الوجبة في الموعد & 9 \\
\hline 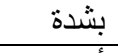 & & & & - & $1, \mathrm{~V}$ & 14,4 & 10 & $\%$ & المحدد & \\
\hline 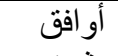 & $r \varepsilon$ & $\cdot, 77$ & $r, 1 \leq$ & - & $\varepsilon$ & 11 & $\leqslant 0$ & S & اشرح للطفل أهمية الغذاء ودوره & r \\
\hline بشدة & & & & - & $7, V$ & $1 \Lambda, r$ & vo & $\%$ & & \\
\hline & & & r & 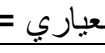 & 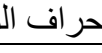 & & & حام = & المتوسط الحسابي & \\
\hline
\end{tabular}


جدول (†): التكرارات والنسب المئوية والمتوسطات الحسابية والانحرافات المعيارية والرتب لإجابات مفردات عينة الاراسة بالنسبة للعبارات المتعلقة بالصعوبات

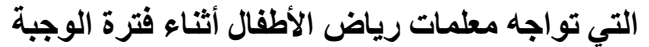

\begin{tabular}{|c|c|c|c|c|c|c|c|c|c|c|}
\hline المواجة & ت العبارة & المعياري الافي & الحسابي & بثدة - مضض & ارفض & او افق & 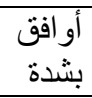 & النسبة & العبار ات & 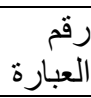 \\
\hline \multirow[t]{2}{*}{ أو افق } & \multirow[t]{2}{*}{1} & \multirow[t]{2}{*}{$\cdot, \wedge)$} & \multirow[t]{2}{*}{$r, \wedge \wedge$} & $\varepsilon$ & $1 \leqslant$ & 19 & $1 \pi$ & ك5 & \multirow{2}{*}{ لا توفر الروضة وجبات صحية بديلة } & \multirow[t]{2}{*}{11} \\
\hline & & & & $7, V$ & $r T, r$ & $\varepsilon \wedge, \Gamma$ & $r_{1, V}$ & $\%$ & & \\
\hline \multirow[t]{2}{*}{ أو افق } & \multirow[t]{2}{*}{ Y } & \multirow[t]{2}{*}{$\cdot, \Lambda T$} & \multirow[t]{2}{*}{$r, \Lambda)$} & $r$ & 17 & $r T$ & 11 & 5 & \multirow{2}{*}{ بالثقافي من الغذائية البرامج التدريبية الخاصة } & \multirow[t]{2}{*}{17} \\
\hline & & & & 0 & $r \uparrow, V$ & $r \wedge, r$ & $r$. & $\%$ & & \\
\hline \multirow[t]{2}{*}{ أو افق } & \multirow[t]{2}{*}{$r$} & \multirow[t]{2}{*}{$\cdot, \wedge$. } & \multirow[t]{2}{*}{$r, \vee \wedge$} & 7 & $1 \leq$ & rA & IT & ك & \multirow{2}{*}{ تجاه وجبة الطفل ارة تليم لسياسات واضحة } & \multirow[t]{2}{*}{11} \\
\hline & & & & 1. & $T r, r$ & $\varepsilon 7, V$ & $r$. & $\%$ & & \\
\hline \multirow[t]{2}{*}{ أو افق } & \multirow[t]{2}{*}{$\varepsilon$} & \multirow[t]{2}{*}{., 70} & \multirow[t]{2}{*}{$r, V \tau$} & Y & 11 & ro & 0 & ك & \multirow{2}{*}{ 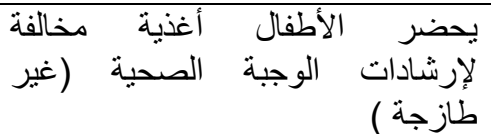 } & \multirow[t]{2}{*}{$\varepsilon$} \\
\hline & & & & $r, r$ & $r$. & $0 \wedge, \Gamma$ & $\Lambda, r$ & $\%$ & & \\
\hline \multirow{2}{*}{ أو افق } & \multirow[t]{2}{*}{0} & \multirow[t]{2}{*}{$\cdot, V T$} & \multirow[t]{2}{*}{ T,TT } & 0 & 19 & $r$. & 7 & 5 & \multirow{2}{*}{ ألجد صعوبة في اقناع الأطفال بتتاول } & \multirow[t]{2}{*}{$r$} \\
\hline & & & & $\Lambda, r$ & $r, v$ & 0. & 1. & $\%$ & & \\
\hline \multirow[t]{2}{*}{ أو افق } & \multirow[t]{2}{*}{7} & \multirow[t]{2}{*}{$\cdot, \wedge I$} & \multirow[t]{2}{*}{ T,70 } & $\varepsilon$ & YI & $r 7$ & 9 & 5 & \multirow{2}{*}{ أجندافة الغذائية في لدى الاطفاون الاسر في تعزيز } & 14 \\
\hline & & & & $7, V$ & ro & $\varepsilon \Gamma, \Gamma$ & 10 & $\%$ & & \\
\hline أو افق & V & $\cdot, V V$ & $r, 00$ & $\varepsilon$ & $T V$ & $r Y$ & $\mathrm{~V}$ & 5 & أو اجه صعوبة في اكساب الطفل ثقافة & 1 \\
\hline & & & & $7, V$ & $\varepsilon 0$ & $r q, v$ & $11, \mathrm{~V}$ & $\%$ & غذائية جيدة & \\
\hline 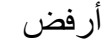 & $\wedge$ & $\cdot, \times 7$ & $r, \leqslant 7$ & $\varepsilon$ & $r q$ & YI & 7 & ك) & ينقص الروضة توفر أدلة لمعلمات & 10 \\
\hline & & & & $7, \mathrm{~V}$ & $\varepsilon \wedge, r$ & ro & $1 \cdot$ & $\%$ & ورياض إجراء الأطفال خاصة بالتغذية & \\
\hline
\end{tabular}




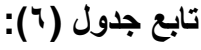

\begin{tabular}{|c|c|c|c|c|c|c|c|c|c|c|}
\hline 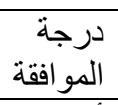 & 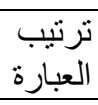 & الانحر افياري & الحتوسط الحسبي & بشدة - ارفض & ارفض & او افق & بشندة أو افق & النسبة & العبار ات & 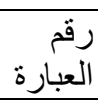 \\
\hline \multirow{2}{*}{ أرفض } & \multirow[t]{2}{*}{9} & \multirow[t]{2}{*}{$\cdot, \vee \leqslant$} & \multirow[t]{2}{*}{$r, \leqslant 0$} & 0 & $r \wedge$ & rY & 0 & 5 & \multirow{2}{*}{ تبربك المتابعة أثناء التوجبة يحضر ها الأطفال مما } & \multirow[t]{2}{*}{0} \\
\hline & & & & $\Lambda, r$ & $\sum 7, V$ & r & $\Lambda, r$ & $\%$ & & \\
\hline \multirow[t]{2}{*}{ أرفض } & \multirow[t]{2}{*}{1.} & \multirow[t]{2}{*}{$\cdot, V Y$} & \multirow[t]{2}{*}{ 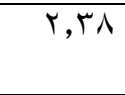 } & 0 & $r$ & $r$. & $\varepsilon$ & 5 & \multirow{2}{*}{ برفض الأطفال تناول الغذاء الصحي } & \multirow[t]{2}{*}{7} \\
\hline & & & & $\Lambda, r$ & $01, \mathrm{~V}$ & $r \mu, r$ & $7, V$ & $\%$ & & \\
\hline \multirow[t]{2}{*}{ أرفض } & \multirow[t]{2}{*}{11} & \multirow[t]{2}{*}{$\cdot, V \leq$} & \multirow[t]{2}{*}{ r, rV } & $\varepsilon$ & $r \varepsilon$ & 17 & 7 & 5 & \multirow{2}{*}{ ونوجيه سلوكهة في متابعة أنتاول الأطفال للوجبة } & \multirow[t]{2}{*}{$r$} \\
\hline & & & & $7, V$ & $07, \mathrm{~V}$ & $Y \uparrow, V$ & 1. & $\%$ & & \\
\hline \multirow[t]{2}{*}{ أرفض } & \multirow[t]{2}{*}{ ir } & \multirow[t]{2}{*}{$\cdot, \vee>$} & \multirow[t]{2}{*}{ T, T } & 7 & $r$. & 19 & 0 & 5 & \multirow{2}{*}{ إلى التحديد مهام عمل المعلمة الخاصة بفترة الوجبة } & \multirow[t]{2}{*}{$1 \varepsilon$} \\
\hline & & & & 1. & 0. & $r, V$ & $\Lambda, r$ & $\%$ & & \\
\hline \multirow[t]{2}{*}{ أرفض } & \multirow[t]{2}{*}{14} & \multirow[t]{2}{*}{ •, } & \multirow[t]{2}{*}{ Y,T } & 7 & $r \varepsilon$ & 11 & $V$ & 5 & \multirow{2}{*}{ يحتاج الأطفال مزيد من الوقت لإكمال الوجبة } & \multirow[t]{2}{*}{$\Lambda$} \\
\hline & & & & 1. & $07, \mathrm{~V}$ & $r I, V$ & $11, \mathrm{~V}$ & $\%$ & & \\
\hline \multirow[t]{2}{*}{ أرفض } & \multirow[t]{2}{*}{$1 \varepsilon$} & \multirow[t]{2}{*}{$\cdot, \vee \vee \varepsilon$} & $r, Y T$ & 7 & $r$ & $1 \leq$ & $\varepsilon$ & 5 & يحد عامل الوقت من أدائي أنثاء فترة الوجبة & $\mathrm{V}$ \\
\hline & & & & 1. & & rT, r & $7, V$ & $\%$ & & \\
\hline 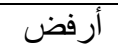 & 10 & $\cdot, \wedge Y$ & T, YV & 9 & 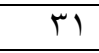 & $1 \leqslant$ & 7 & 5 & يعتبر مكان الوجبة غير مهيأ وغير مناسب & 9 \\
\hline & & & & 10 & $01, \mathrm{~V}$ & rT, r & $1 \cdot$ & $\%$ & لتناول الأطفال للوجبة & \\
\hline 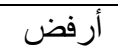 & 17 & $\cdot, V Y$ & $r, \cdot \Lambda$ & 11 & $r V$ & 1. & $r$ & 5 & تفتقر الروضة للتخطيط المسبق لفترة الوجبة & iv \\
\hline & & & & $1 \wedge, r$ & $71, \mathrm{~V}$ & $17, \mathrm{~V}$ & $r, r$ & $\%$ & & \\
\hline 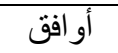 & IV & $\cdot, \vee \vee 1$ & r,IV & 7 & $\mathrm{~V}$ & $\wedge$ & rq & 5 & اجد صعوبة في اقناع الطفل بترك الأغذية & 1 . \\
\hline & & & & 1. & $11, \mathrm{~V}$ & $1 T, r$ & 70 & $\%$ & المحتوية على الوان صناعبة & \\
\hline 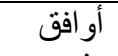 & 11 & $\cdot, \wedge$. & $r, \leqslant 0$ & - & $r$ & $\wedge$ & 0. & 5 & أعاني من قلة حلقات التثقيف الغذائي لأمهات & 11 \\
\hline 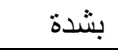 & & & & - & $r, r$ & $1 T, r$ & $\Delta r, r$ & $\%$ & & \\
\hline & & & $\cdot, \varepsilon$ & 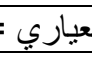 & 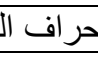 & & & $1=\frac{6}{2}$ & المتوسط الحسابي ال & \\
\hline
\end{tabular}


دور معلمات رياض الأطفال أثناء فترة الوجبة في إكساب الثقافة الغذائية لأطفال الروضة بعفف، المدلكة العربية السعوبية

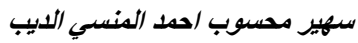

\title{
Role of Kindergarten Teachers During the mealtime in achieving the nutritional knowledge of Kindergarten Children in Afif city, Kingdom of Saudi Arabia
}

\author{
Soheir M. El-deab
}

- Assistant Professor and Head of Home Economics, Faculty of Education of Afif, Shakra University, Saudi Arabia

\section{ABSTRACT:}

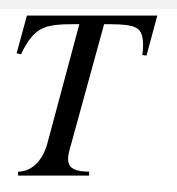

he study aimed to identify the role of kindergarten teachers during the mealtime in providing nutritional knowledge of the kindergarten child. To achieve this, a descriptive method was used.

The questionnaire was used as data collection tool. The sample consisted of (60) Kindergarten Teachers. In the analysis of the data, the study showed that the tool obtained an average of (2. 95 from 4. 00) and at the field level Axis concept of nutritional knowledge (2. 88). Followed by the difficulty of kindergarten teachers during the mealtime, teachers were at an average of (2.49). Both of which are rated (High), while very high on (kindergarten teacher practices during the mealtime at an average of (3.46).The teachers also showed that the meals attended by the children are healthy and that there is awareness among the families about the type of food provided to the children. In the light of the results of this study, a number of recommendation and suggestions are made to introduce the food culture of the child as judges in the rehabilitation and training of nannies and teachers.

Key words: mealtime, Food Culture, Kindergarten 